\title{
Techno economic and environmental assessment of wind assisted marine propulsion systems
}

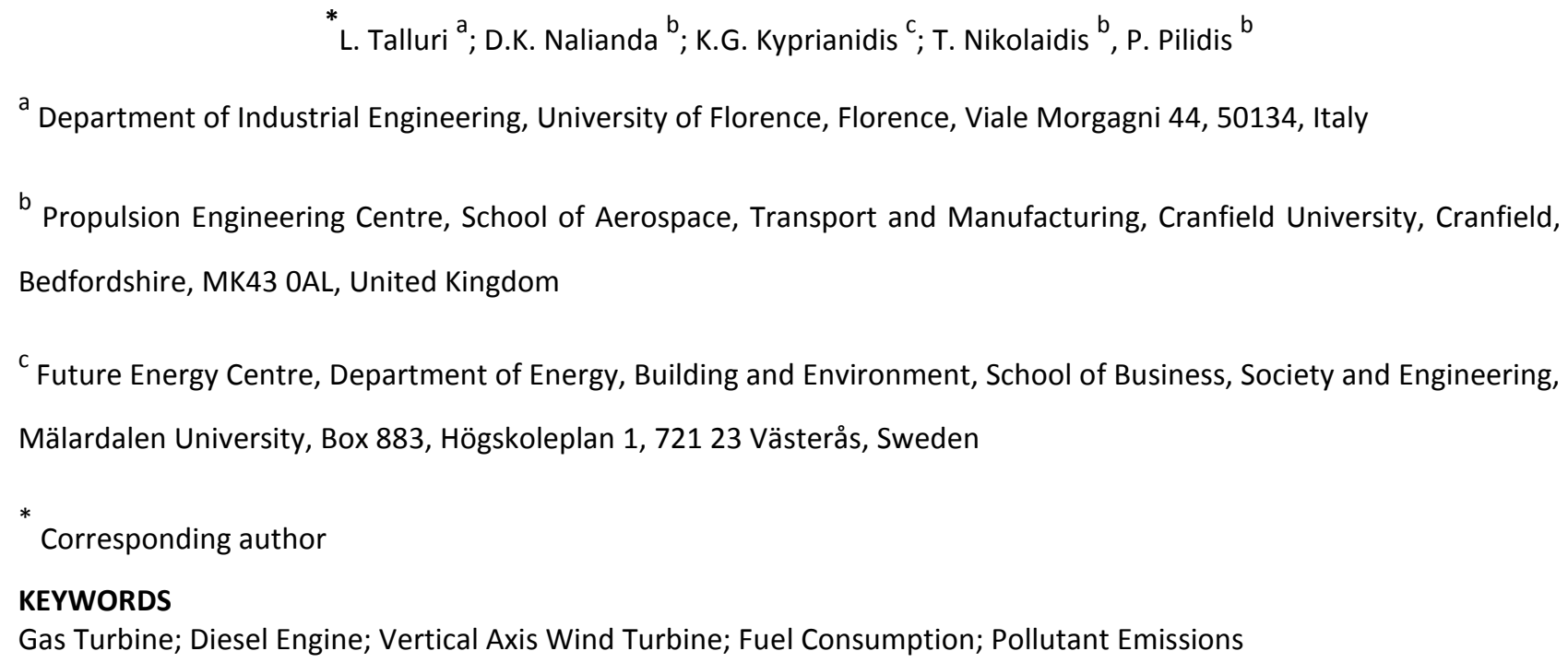

\section{Online Abstract submitted (191 words)}

The increase in marine fuel prices coupled with stricter regulations on pollutant emissions set by the International Maritime Organization have promoted the research in new propulsion technologies and the utilization of cleaner fuels. This paper describes a novel methodology to enable quantifying and evaluating the environmental and economic benefits that new technologies and fuels could allow in the marine sector.

The proposed techno economic and environmental analysis approach enables consistent assessment of different traditional propulsion systems when operated in conjunction with a novel environmental friendly technology, while operating on typical Sea Lines Of Communication.

The study demonstrates the benefits of the installation of two vertical axis wind turbines on the deck of a ship in conjunction with conventional power plants. For the missions selected, the analysis indicates that the performance of the wind turbines and the corresponding benefits strongly depend on the routes and environment in which they operate allowing fuel savings from $14 \%$ (in the gas turbine case) to $16 \%$ (in the diesel engine case). Additionally, the analysis presented highlights benefits of using a conventional gas turbine burning natural gas when compared against a diesel engine burning marine diesel oil.

\footnotetext{
*Corresponding author. Tel.: +393484945087 , E-mail address: lorenzo.talluri@unifi.it 


$\begin{array}{ll}\text { NOMENCLATURE } \\ \text { CNG } & \text { Compressed Natural Gas } \\ \text { COGOW } & \text { Climatology of Global Ocean Winds } \\ \text { dS } & \text { Change distance } \\ \text { dt } & \text { Change time } \\ \text { EES } & \text { Engineering Equation Solver } \\ \text { HAWT } & \text { Horizontal Axis Wind Turbine } \\ \text { HFO } & \text { Heavy Fuel Oil } \\ \text { IMO } & \text { International Maritime Organization } \\ \text { LNG } & \text { Liquid natural gas } \\ \text { MARPOL } & \text { Marine pollution } \\ \text { MDO } & \text { Marine Diesel Oil } \\ \text { O\&M } & \text { Operation and Maintenance } \\ \text { SFC } & \text { Specific Fuel Consumption } \\ \text { TERA } & \text { Techno-economic Environmental Risk } \\ & \text { Analysis } \\ \text { TRL } & \text { Technology Readiness Level } \\ \text { V } & \text { Velocity of the vessel } \\ \text { VAWT } & \text { Vertical Axis Wind Turbine } \\ V_{\text {ref }} & \text { Reference Wind Velocity } \\ \text { Emissions } & \\ \text { CO } & \\ & \text { Carbon Dioxide }\end{array}$

$\begin{array}{ll}\text { NOx } & \text { Nitrogen oxide } \\ \text { SOx } & \text { Sulphur oxide } \\ \text { Finance } & \\ \$ & \text { Dollars } \\ \$ / k W & \text { Dollars per kilowatt } \\ \$ / m m B T U & \text { Dollars per million British thermal unit } \\ \$ / \mathrm{t} & \text { Dollars per tonne } \\ \$ / y & \text { Dollars per year } \\ \mathrm{CF}_{\mathrm{j}} & \text { Cash flow at year } \mathrm{j} \\ \mathrm{i} & \text { Discount Rate } \\ \mathrm{I}_{0} & \text { Initial investment } \\ \text { IR } & \text { Inflation rate } \\ \text { IRR } & \text { Internal rate of return } \\ \mathrm{j} & \text { Year number } \\ \mathrm{M} \$ & \text { Million Dollars } \\ \mathrm{M} \$ / \mathrm{y} & \text { Million Dollars per year } \\ \mathrm{n} & \text { Total number of years } \\ \mathrm{NBP} & \text { National Balancing Point } \\ \mathrm{NPV} & \text { Net present value } \\ \mathrm{NPV} & \text { Net present value at 20 years } \\ \mathrm{PBT} & \text { Payback period }\end{array}$

\section{ABSTRACT}

In recent years, the increase in marine fuel prices coupled with stricter regulations on pollutant emissions set by the International Maritime Organization have promoted the research in new propulsion technologies and the utilization of cleaner fuels. This paper describes a novel methodology to enable quantifying and evaluating the environmental and economic benefits that new technologies and fuels could allow in the marine sector.

The proposed techno economic and environmental analysis approach enables consistent assessment of different traditional propulsion systems (diesel engine and gas turbine) when operated in conjunction with a novel environmental friendly technology, such as a vertical axis wind turbine. The techno-economic and environmental assessment is focused on the potential reduction in fuel consumption and pollutant emissions that may be accrued while operating on typical Sea Lines Of Communication (Mediterranean, North Sea, Atlantic).

The study demonstrates the benefits of the installation of two vertical axis wind turbines on the deck of a ship in conjunction with conventional power plants. The analysis indicates that the performance of the wind turbines and the corresponding benefits strongly depend on the routes and environment in which they operate (therefore favourable wind conditions) allowing fuel savings from $14 \%$ (in the gas turbine case) to $16 \%$ (in the diesel engine case). The study also indicates that possible benefits may diminish for weak wind conditions.

The results reported in this paper establish the economic benefits of installing vertical axis wind turbines in conjunction with conventional technology (Diesel and Gas Turbine Power plants) when installed on a ship travelling through the Atlantic Ocean. The primary purpose of this study is to introduce a methodology to demonstrate the application, performance and economic benefits of the technology at a preliminary design phase and further form a foundation for more elaborate analysis on the subject in the future. 


\section{INTRODUCTION}

Shipping is one of the most critical means of transportation for sustaining the global economy. It is an economical means for sustaining the international import and export markets whilst enabling global distribution of cargo. The rapid growth of global economies and the corresponding sharp rise in the requirement to transport large scale cargo has primarily been responsible for accelerated development of technology in the shipping industry over the last few decades.

The sustainability of the shipping industry, as any other industry, depends on the elasticity of demand for the service and the profitability through minimising operating costs. These costs in the past have largely depended on the price of marine fuels, but with environmental emissions now being in the forefront, this trend is set to change. A good example of this trend is the introduction of new environmental compliance standards through Marine Pollution (MARPOL) annex VI (Marine Environment Protection Committee, 2011) and the potential introduction of carbon taxes.

Assessing and understanding the interdependency and effects of environmentally optimised solutions and emission mitigation policies along with the adaptation of more fuel efficient solutions will be paramount. Consequently, research on environmentally sustainable marine propulsion solutions in recent years has endeavoured to address precisely these issues (García-Martos, C., et al., 2013; Notteboom, T.E., and Vernimmen, B., 2009). Studies have also shown that the current global marine propulsion could be improved through the introduction of new propulsion technologies and by the utilization of cleaner fuels (Hirdaris, S.E., et al., 2014; Vergara, J., et al., 2012; Alfonsín, V., et al., 2014).

\subsection{Power plants in the Marine Environment}

The power plants for marine propulsion are primarily heat engines. These comprise steam turbines, gas turbines and reciprocating engines which run on conventional thermodynamic cycles. The selection of power plants is influenced by a significant number of factors which may include technical requirements, economic criteria and political influence. Hence, it may determine the predominance of one system over the other. However, with the energy crisis of 1974 and the significant improvements in the diesel reciprocating engine technology, the utilisation of steam and gas turbine cycles in the marine power plants significantly reduced due to their lower efficiency (Woodyard, D., 2004).

It may be noted that even though the majority of commercial vessels are powered by diesel engines, (El-Gohary. M.M., 2013), the gas turbine power plant has played a predominant and critical role in the military sector. With significant improvements in gas turbine cycle efficiency now being realised, the marine commercial sector has now witnessed an increased exploitation and application of the technology. This has specifically been seen in fast ferries and fast cargo ships as a consequence of its characteristic high power to weight ratio.

\subsection{New technologies and fuels}

In recent years, a significant amount of research and a number of studies have been undertaken on new technologies and fuels in the context of marine power plants. Parker, J (2013) offers an overview of the future of marine propulsion and the novel propulsion technologies that may be considered. His research has indicated that these technologies 
(nuclear propulsion, batteries, fuel cells, superconducting electric motors, renewable energies, Organic Rankine Cycle and hybrid propulsion) will be necessary (and need to be significantly developed) in order to overcome the fuel consumption and environmental issues impact.

On similar lines and in order to ensure the future environmental sustainability of marine propulsion, a significant number of important studies have been undertaken. Some of these include research which propose the use of nuclear energy for merchant marine propulsion (Hirdaris, S.E. et al., 2014), consider the possibility of the addition of a waste heat recovery system combined with a conventional power plant (Burel, F., et al., 2013; Livanos, G.A., et al. ,2014) and highlight the necessity and thereby proposing the development of a renewable energy infrastructure for marine propulsion (Huaa, J., et al. ,2008).

Several studies have also been undertaken on the application of wind propulsion technologies for marine application as a renewable source of energy. Some of the key ones include those by Leloup, R., et al., (2014), Traut, M., et al., (2014), Rojon, I., and Dieperink, C., (2014) and Bergeson, L., et al., (1985).

Apart from environmental friendly technologies a significant amount of research has also been undertaken on cleaner fuels with an aim to develop possible solutions to reduce environmental emissions. Studies by Alfonsín, V., et al., (2014) and Andrews, J. (2012) have highlighted the application of Hydrogen as a possible alternative for a sustainable propulsion system, while Brynolf, S., et al. (2014) compare the environmental performance of liquefied natural gas (LNG) and several biofuels.

The burning of natural gas for marine propulsion however is not an innovative idea, as it has been previously used in LNG carriers. Natural gas can be employed in compressed (Compressed Natural Gas - CNG) or in liquefied form (Liquefied Natural Gas - LNG). CNG volume is $1 \%$ of the volume it holds at standard atmospheric pressure. It is compressed and stored at pressure of 200 - 250 [bar], commonly in high pressures cylinders. LNG attains an even higher reduction in volume and consequently, the energy density of LNG is 2.4 times that of CNG or $60 \%$ of that of diesel (McGill, R., et al., 2013).

The advantage between LNG and CNG is that the former requires less space for fuel tanks and also requires lesser time to refuel the ship and hence making it more suitable for long routes in comparison. The advantages of CNG include lower prices and fewer changes needed in terms of supply infrastructure compared to LNG. Research by Parker, J. (2013) has highlighted the main advantages and drawbacks of Natural Gas for marine propulsion. The main advantages include the fact that it is a known technology with relevant and significant benefits of reduced SOx, NOx and particulate matter emissions while being a cheaper fuel than distillate marine fuel. Some of the key disadvantages of natural gas as a fuel is that it has higher fuel storage and safety requirements in comparison to conventional fuels and also lacks worldwide supply infrastructure. However, it is now becoming increasingly important as a marine fuel, owing to drop in prices in natural gas and introduction of environmental legislations which favour it as a replacement to marine diesel oil. Hence it is now being proposed as one of the most promising solutions. In their research Burel, F., et al., (2013) suggest that a reduction of $35 \%$ in operational costs and $25 \%$ in $\mathrm{CO}_{2}$ emissions may be expected when LNG is implemented on a 33,000 deadweight tanker ship. 
Wind energy was one of the key sources of propulsive power on ships in ancient times. However as a renewable, abundant and free source of energy, it has not been adequately exploited by the shipping industry in recent times. It is opined that winds in the open sea are more suitable for producing power than winds on land, as they lose lesser energy thereby resulting in lower reduction in velocity due to friction. Therefore, wind propulsion for the marine sector has the potential of being the "old but beneficial" technology that could allow significant fuel and emissions reduction. Compared to other renewable solutions, it has the advantage of being always available in open sea and fairly well known in terms of exploitation. It may be retrofitted on an already existing ship as an alternative source of power, which is less complicated to achieve compared to nuclear power and solutions utilising hydrogen as a fuel.

Consequent to increasingly important environmental issues and the rising prices of fossil fuels, as discussed earlier, consideration is now being given to utilising wind energy as an alternative and additional source of power to assist conventional propulsion systems on ships. The new term for these wind energy propulsion technologies is "windassisted" and refers to vessels in which most of the power is produced by the traditional propulsion technologies like diesel engines or gas turbines, and a fraction of the overall required power is delivered by wind energy technologies. This is primarily aimed at decreasing overall fuel consumption and environmental emissions. There are several wind power technologies that have been developed for marine propulsion and mostly include stayed fore and aft rig, unstayed cat rig, Princeton sail-wing, square rig, wing sail, Flettner rotor, horizontal axis wind turbine, vertical axis wind turbine and kites (Bergeson, L., et al., 1985).

There have been several interesting studies undertaken on sail assisted ships (Shukla, P.C., and Kunal, G., 2009; Lambrecht, M., et al., 1994) and on horizontal-axis wind turbine combined for marine propulsion (Bockmann, E., and Steen, S., 2011). However there exists a literature gap in the full investigation of the vertical axis wind turbine technology for marine propulsion.

\subsection{Horizontal and Vertical Axis Wind Turbines in the Marine Environment}

Generally, the horizontal-axis wind turbine's (HAWT) performance is superior compared to the equivalent class of vertical-axis wind turbine (VAWT), primarily attributed to the higher efficiency and the higher power produced for the equivalent area (Pope, K., et al., 2010). In comparison to HAWTs, VAWTs may also have additional issues leading to poor performance. These issues include low aerodynamic efficiency, fluctuation of the torque on the shaft and problems with start-up due to requirements of higher wind velocity to set the rotor in motion.

VAWT as a concept does however have some very favourable features in comparison to HAWT, especially when applied to the marine world. They offer greater ease of production and consequently lower capital costs. One important aspect where a VAWT as a design concept is found beneficial in terms of installation on ships is the centre of mass of the device. VAWTs have lower centres of mass than HAWTs, which is very beneficial in order to avoid increasing the heeling moment of the ship and also increases the stability of the structure while reducing the oscillations of the supporting tower.

VAWTs are less complex as the turbine does not necessarily need to be aligned to the wind direction and hence does not require any additional mechanism like a "Blade Pitch System" or a "Yaw Control". These mechanisms are of critical 
importance to HAWTs and consequently result in a higher design and investment cost. The ability of the VAWT to adapt to any wind direction may be considered to be the most significant advantage when compared to all the other wind assisted technologies for marine propulsion, and hence, makes it ideal for utilisation in sites with high variable wind direction.

A further beneficial quality of the VAWT is the lower operating costs. This is attributed to the lower complexity of the machine and to the location of the gearbox and the generator, which are placed near the ground (the deck when considering the marine application), thereby significantly lowering the operating and installation costs.

As a consequence of these favourable features, the limited literature available on the application of the concept, and the drive to move increasingly towards electric architectures for marine applications, the vertical axis wind turbine was selected as the wind assisted propulsion system to be analysed in this work.

The principal aim of this study is to therefore investigate the application of wind assisted propulsion systems along with various marine propulsion systems, in order to assess the preferred solution, from an environmental and an economic perspective. To evaluate the optimum alternative, the concept of techno economic environmental and risk analysis (TERA) was adapted to this work. Conceptualised at Cranfield University the framework essentially constitutes a multi-disciplinary optimisation framework that can quantify risks as well as compare and rank competing schemes on a formal and consistent basis. The technique is based on detailed and rigorous thermodynamic representations of power plants, integrated with other appropriate models. The TERA concept has been successfully and extensively been utilized for aerospace applications (Kyprianidis K.G., et al., 2008; Ogaji, S.O.T., et al., 2009; Kyprianidis K.G., et al., 2011). The framework configured for marine research has also been applied for marine propulsion research (Doulgeris, G., et al., 2012; Bonet, M.U., et al., 2010). The framework, when used for marine propulsion research, integrates a wide range of performance prediction and simulation models which include those for marine engine performance, marine vessel design and performance simulation, gaseous emissions prediction and operational economics. Other relevant research on techno-economic analysis in the marine sector have also been developed by Theotokatos, G. and Livanos, G.A., (2013) and Livanos, G.A., et al., (2014).

To summarise, the literature review has indicated a significant gap in the study of wind assisted technologies for ship propulsion. It is therefore opined that there exists a strong need to conduct preliminary assessments and quantify the benefits that may be accrued through the application at such technologies. The objective of this study will be to therefore, apply the TERA concept to address this gap. This will be achieved by investigating and establishing the benefits of the implementation of two VAWTs on the deck of a cargo ship. The study will analyse the integrated marine propulsion system from a performance, environmental and an economic perspective.

\section{METHODOLOGY}

\subsection{TERA framework}

Techno-economic Environmental Risk Analysis (TERA) essentially comprises a framework of mathematical models to simulate the performance of a single or a set of technologies. The framework allows an increased visibility of risks, whilst enabling the user to compare and rank competing schemes on a formal and consistent basis, so that investment resources may be allocated efficiently (Goulos, et al., 2010; Najafi Saatlou, et al., 2014; Doulgeris, G., et.al. 2012). 
The framework (figure 1 ) is modular in structure and consists of a set of core models, which allow simulation of detailed power-plant systems, with component physics-based mathematical models. The core models can be further coupled with a wide range of environment, economic and risk models. The assessments are conducted on a system and mission level and may be used to deliver an insight into the relative risks and benefits of promising but uncertain concepts, at lower TRLs (Technology Readiness Level) of development.

Technology Readiness Levels (TRL) are a type of classification system used to assess the maturity level of a particular technology (NASA, 2014). Each technology project is evaluated against the parameters for each technology level and is then assigned a TRL rating based on the projects progress. There are nine technology readiness levels. TRL 1 is the lowest and TRL 9 is the highest.

The TERA utilising this classification system offers an independent and consistent evaluation procedure to assess the maturity of evolving technologies during their development process and additionally allows comparative studies of complex systems, encompassing local and global conditions.

TERA has been used extensively in the past to conduct design space exploration and trade-off studies, parameter sensitivity analysis, asset management and multi-disciplinary optimisation (Kyprianidis, et al., 2011; Kyprianidis, et al., 2014; Xu, et al., 2013; Najafi Saatlou, et al., 2014; Camilleri et al., 2014). Frameworks that utilise a similar approach to TERA have also been used successfully by other researchers in the field for novel technology assessments (Marinai, L., et.al. 2004; Alexiou, et al., 2012).

This study utilises a TERA model framework to produce a set of performance, environmental and economic assessments in order to investigate a feasible and profitable solution for the reduction of gaseous emission and fuel consumption in the shipping industry. 


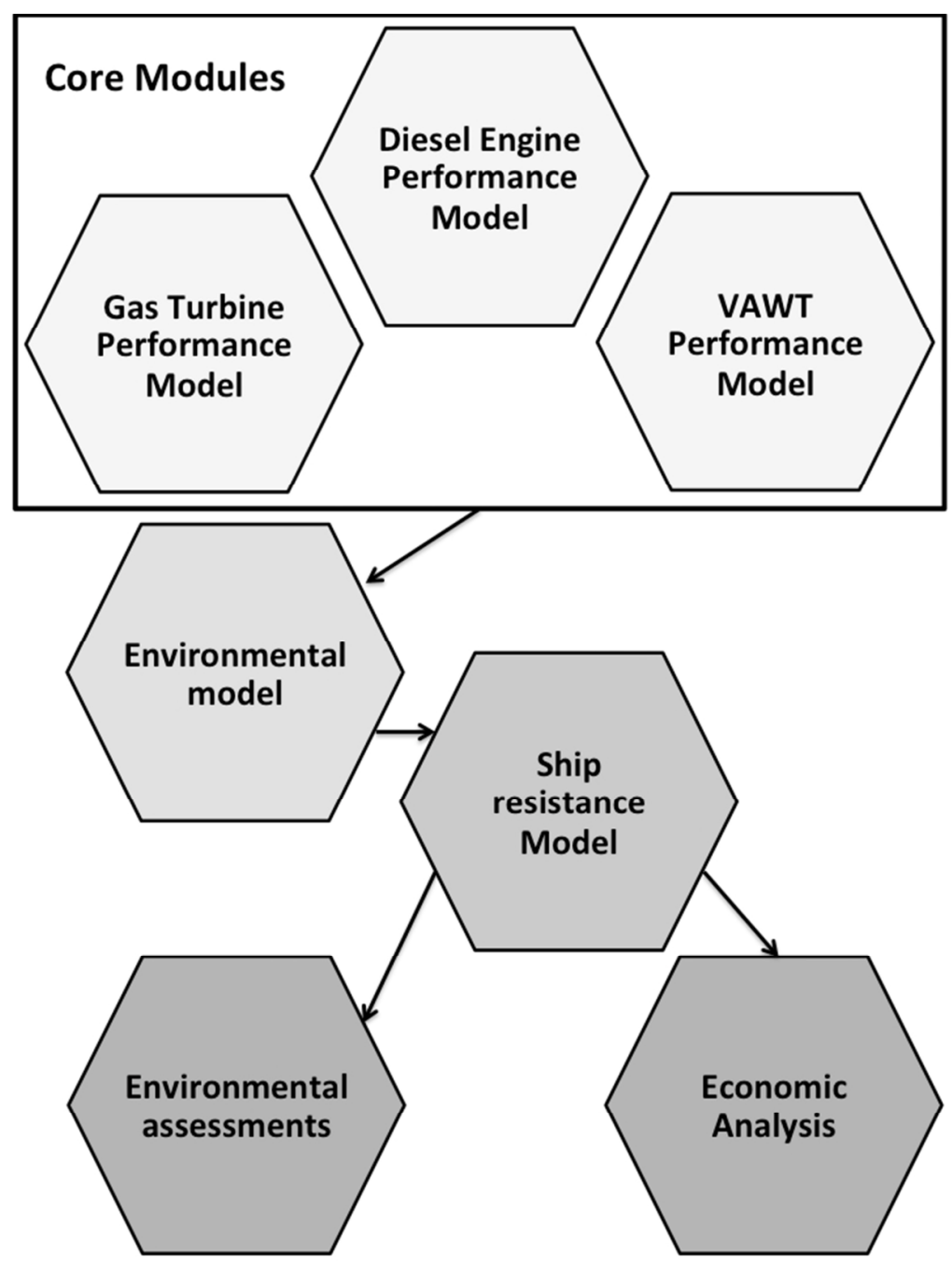

Figure 1 Schematic of TERA framework

The TERA analysis initially requires defining the kind of technologies to assess. In this case study this entailed the selection of the class of the ship to be used as a platform for the integration of the novel propulsion system. The core modules included in the TERA framework enable the simulation of the performance of a Marine vehicle, gas turbine propulsion system, diesel engine propulsion system and a Vertical Axis Wind turbine. The core simulation models are then further integrated into the framework to predict environmental emissions, the weather to simulate atmospheric conditions for selected mission/routes and analyse economic performance.

\subsection{A description of TERA modelling modules}

\subsubsection{Ship model}

The marine vessel selected for the study was based on Dongbang Challenger, a specialist ro-ro steel transporter (Lingwood, J., 1999). The vessel satisfies the requirements of low design speed. Additionally the deck of the ship is assumed to be free of obstructions, to enable locating the vertical axis wind turbines. Specifications of the vessel are listed in table 1. 


\begin{tabular}{cl}
\hline Overall Length & $126.31[\mathrm{~m}]$ \\
\hline Moulded Breadth & $20.00[\mathrm{~m}]$ \\
\hline Moulded Depth (to upper deck) & $11.50[\mathrm{~m}]$ \\
\hline Displacement & $11,012[\mathrm{t}]$ \\
\hline Service Speed & $14.5[\mathrm{knots}]$ \\
\hline
\end{tabular}

Table 1 Main characteristics of the simulated vessel (Lingwood, J., 1999)

\subsubsection{Gas Turbine Model}

One of the primary propulsion systems for the vessel was assumed to be a gas turbine. A performance model of the power plant was developed using an in-house gas turbine performance software (Macmillan, 1974) and was based on a 4.5 [MW] simple cycle two shaft marine gas turbine. The simulated reference point for the powerplant has been based on published data of existing commercial gas turbines and are listed in Table 2. The emissions $\left(\mathrm{CO}_{2}\right.$ and $\left.\mathrm{NOx}\right)$ for the fuel burnt through the gas turbine was predicted using an in-house emission prediction software (Celis, C. 2010).

Performance characteristics at Reference Point

\begin{tabular}{cc}
\hline Ambient Pressure & Sea level (101 [kPa]) \\
\hline Ambient Temperature & $288.15[\mathrm{~K}]$ \\
\hline Efficiency & $32[\%]$ \\
\hline Exhaust gas temperature & $838[\mathrm{~K}]$ \\
\hline Exhaust mass flow & $16.3[\mathrm{~kg} / \mathrm{s}]$ \\
\hline Heat rate & $11,520[\mathrm{~kJ} / \mathrm{kWh}]$ \\
\hline Power & $4,470[\mathrm{~kW}]$ \\
\hline Pressure Ratio & 14.5 \\
\hline Specific Fuel Consumption & $0.269[\mathrm{~kg} / \mathrm{kWh}]$ \\
\hline
\end{tabular}

Table 2 Commercial Marine Gas Turbine characteristics 


\subsubsection{Diesel Engine Performance Model}

The data for the performance simulation of the diesel engine propulsion system was based on the available information of commercial engine (MAN B\&W, 2013) installed on the reference ship. The specific fuel consumption curve, at constant engine speed (750 RPM), when utilizing HFO or MDO, was obtained by linear interpolation of the reference diesel engine data (figure 2).

NOx and $\mathrm{CO}_{2}$ emissions predictions were based on data available in the public domain for the engine. The available literature suggests $560-620[\mathrm{~g} / \mathrm{kWh}]$ and $8-10[\mathrm{~g} / \mathrm{kWh}]$ for $\mathrm{CO}_{2}$ and NOx respectively. The study assumes a mean value of the range indicated (MAN B\&W, 2013; Marine Environment Protection Committee, 2009).

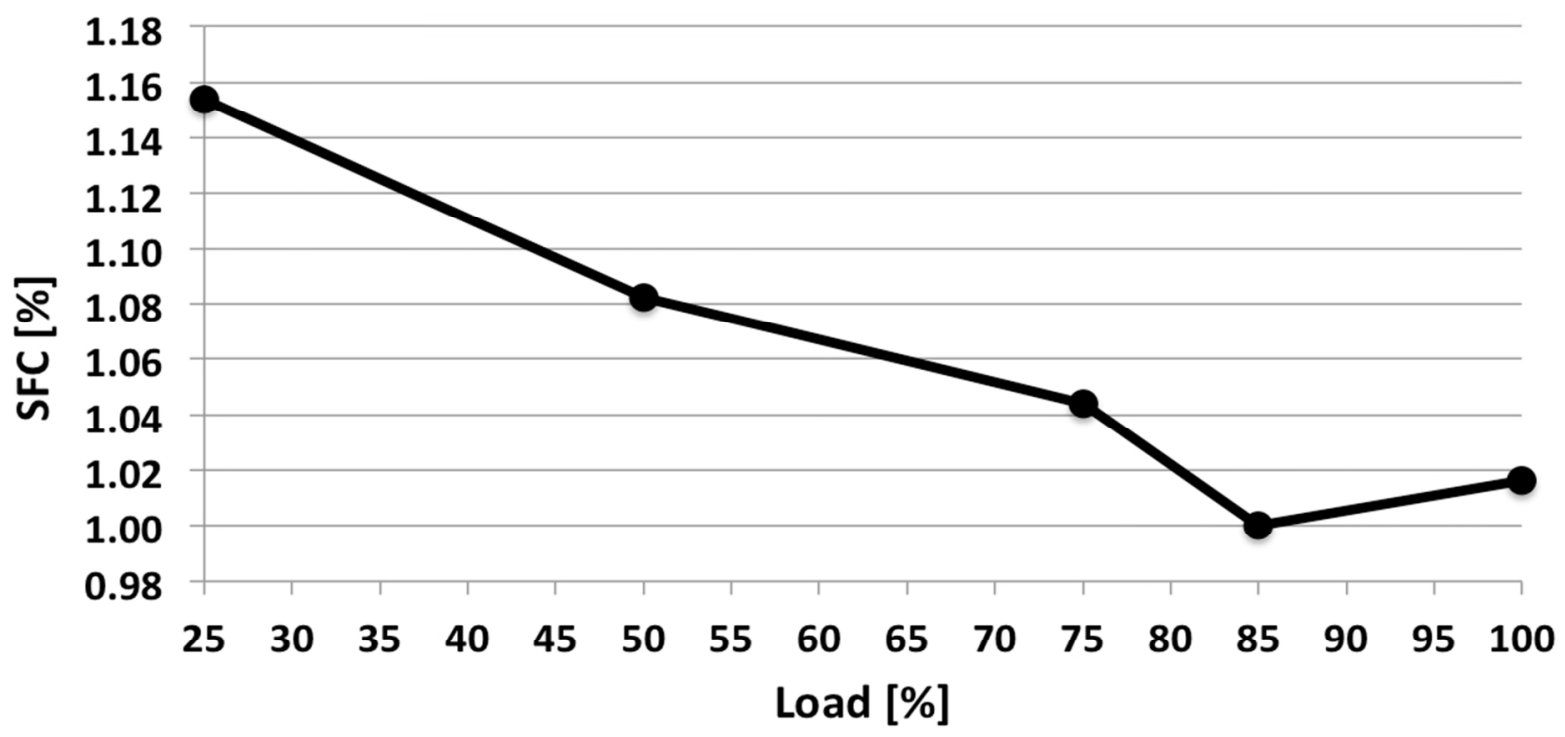

Figure 2 L32/40 specific fuel consumption referred to 85\% load, at the design conditions of 298 [K], 101 [kPa] and relative humidity of $30 \%$

\subsubsection{Vertical Axis Wind Turbine (VAWT) performance model}

The Vertical Axis Wind Turbine model was based on the Hirsch and Mandal model, also known as the cascade model (Hirsch, H., and Mandal, A.C., 1987). This model is based on the standard turbomachinery (Compressor cascade) theory, and particularly on the concept of "row of blades". The key design characteristics of the simulated VAWT are as listed in table 3.

The power generated by the VAWT is a function of wind velocity. The power was therefore calculated utilising interpolation methods applied to selected wind values. The power generated by the wind turbine is related to the third power of wind intensity. Figure 3 displays the power generated from the 2 installed VAWTs in various wind conditions. As can be noted, for high wind intensity, the VAWTs contribution to power generation would be extremely relevant.

Another important feature of the model is its ability to account for the additional resistance that the installation of the wind turbines would produce to the ship in motion, due to air friction. This drag force is obtained through the calculation of the total pressure loss over the row of blades, both in the upstream (first half of a revolution $\left(180^{\circ}\right)$ ) and 10 
downstream (second half of a revolution $\left(180^{\circ}\right)$ ) sections of the wind turbine. Figure 3 displays the additional power required from the installation of the 2 VAWTs on the deck of the selected ship. In particular, the additional power is related to the second power of wind intensity.

The net gain derived by the installation of the VAWTs is the difference between the two contributions, the power generated and the increased power required due to the additional drag, displayed in figure 3.

Nowadays, the most common combination of engines is implemented thanks to the widespread use of electric design. The electric design is set up on the production of electric energy rather than mechanical energy by the power plants. This solution is the one that seems to have the most advantages, as it permits a combination with the new propulsion technologies, such as VAWTs. Therefore in this study it was assumed that all of the devices will feed a common electrical bus bar from which power will be drawn for the propulsion of the ship.

The desired effect, that is fuel consumption reduction, is obtained through the reduction of the power required by the common electrical bus bar from the main prime mover.

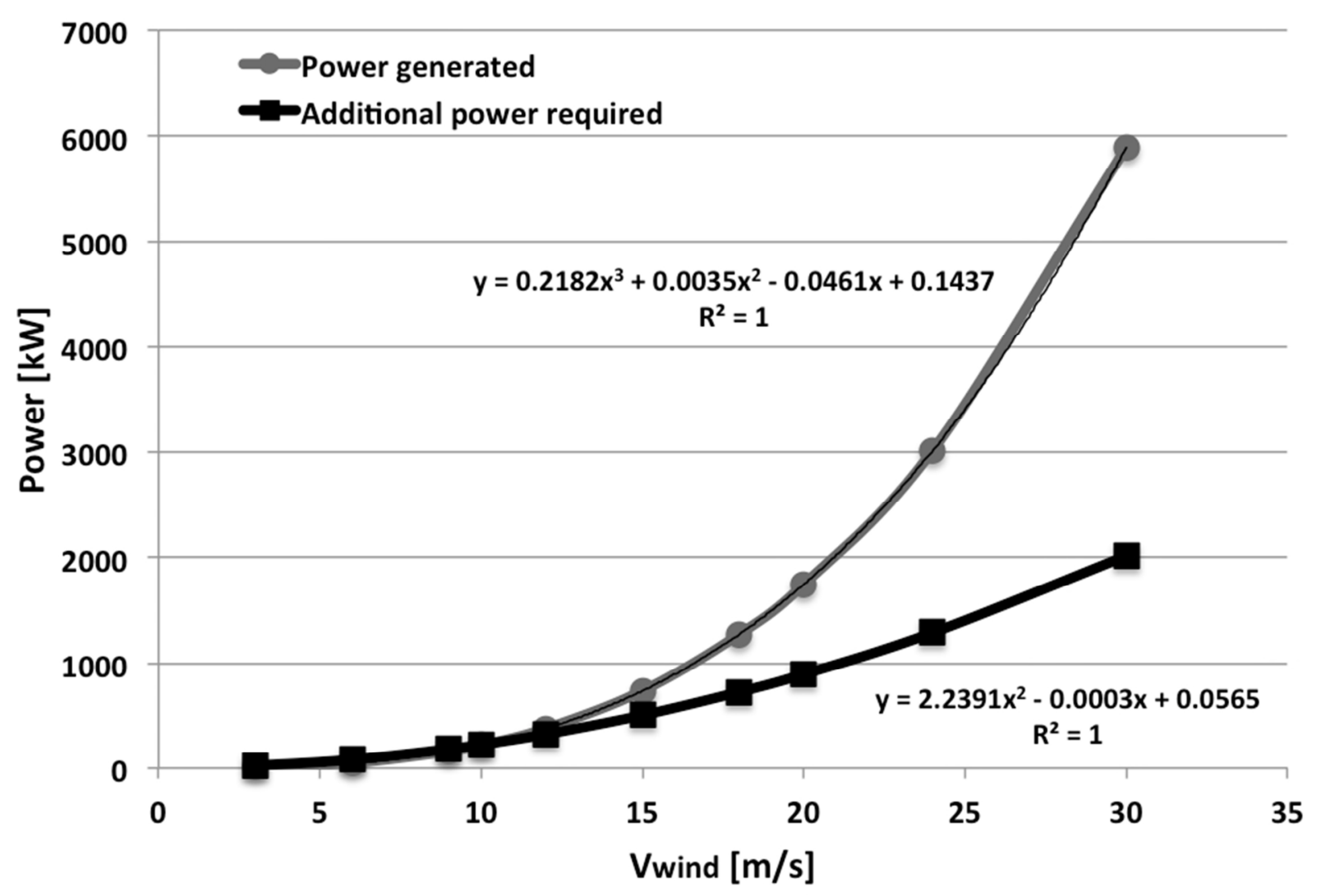

Figure 3 VAWTs power generated and required power to overcome additional drag due to the installation of the wind turbines against wind intensity 


\begin{tabular}{cc}
\hline Blade profile & NACA 0018 \\
\hline Chord of the blade & $0.8[\mathrm{~m}]$ \\
\hline Height & $20[\mathrm{~m}]$ \\
\hline Number of blades & 3 \\
\hline Radius & $9[\mathrm{~m}]$ \\
\hline Reference wind velocity $\left(\mathrm{V}_{\text {ref }}\right)$ & $15[\mathrm{~m} / \mathrm{s}]$ \\
\hline Rotational speed at $\mathrm{V}_{\text {ref }}$ & $54.95[\mathrm{~m} / \mathrm{s}]$ \\
\hline Solidity & 0.267 \\
\hline Tip speed ratio & 3.45 \\
\hline
\end{tabular}

Table 3 Simulated Vertical Axis Wind Turbine Data

\subsubsection{Ship resistance model}

The ship resistance model has been presented in detail in (Doulgeris, G., et al., 2012). The model is essentially divided into five sub-modules.

\subsubsection{Engine Performance}

The sub-module has a three-dimensional interpolation function, which obtains the power of the engine at each operating point. The values have been attained varying turbine entry temperatures and ambient conditions through the Gas Turbine performance and have been stored as a 3D table.

\subsubsection{Marine vessel power prediction routine}

This sub-module is used to determine the hydrodynamic and aerodynamic resistance of the ship. This enables the estimation of the power required by the installed prime movers to provide to the vessel in order to keep the desired velocity.

The model follows the Holtrop and Mennen method, for determining the required propulsive power of the ship (Holtrop, J., and Mennen, G.G.J., 1982). Furthermore, the aerodynamic resistance of the ship was simulated by applying the Jensen method (Schneekluth H., and Bertram, V., 1998) for head wind case and the Blendermann model for all the other cases (Blendermann, W., 1993). The model does not however consider the effects of shallow water in the hydrodynamic resistance module. The effects of propeller cavitation were also not taken into account. 
Consequently, the resistance modules that are implemented to obtain the power requirements of a vessel are given by equation 1.

$\mathrm{R}_{\mathrm{T}}=\mathrm{R}_{\mathrm{V}}+\mathrm{R}_{\mathrm{app}}+\mathrm{R}_{\mathrm{w}}+\mathrm{R}_{\mathrm{Bow}}+\mathrm{R}_{\mathrm{TR}}+\mathrm{R}_{\mathrm{A}}+\mathrm{R}_{\mathrm{AA}}+\mathrm{R}_{\mathrm{B}}+\mathrm{R}_{\mathrm{WT}}$

Where:

- $\mathrm{R}_{\mathrm{t}}$ is the total resistance of the ship

- $\mathrm{R}_{\mathrm{V}}$ is the viscous resistance of the hull

- $R_{\mathrm{app}}$ is the ship appendages resistance

- $\mathrm{R}_{\mathrm{w}}$ is the wave resistance

- $\mathrm{R}_{\mathrm{Bow}}$ is the bow-thrusters resistance

- $\mathrm{R}_{\mathrm{TR}}$ is the additional pressure resistance due to the immersed transom stern

- $\mathrm{R}_{\mathrm{A}}$ is the model-ship correlation resistance

- $\mathrm{R}_{\mathrm{AA}}$ is the wind resistance

- $\mathrm{R}_{\mathrm{B}}$ is the additional pressure resistance of bulbous bow near the water surface

- $\mathrm{R}_{\mathrm{WT}}$ is the additional wind resistance due to the installation of the wind turbines

The calculation of the viscous resistance of the hull $R_{v}$ is based on the statistical method proposed by Holtrop (Holtrop, J., et al., 1982) and uses a frictional model provided by the ITTC-1957 friction formula. The appendage resistance $R_{a p p}$ is determined from referenced literature (Holtrop, J., et al., 1982). They are functions of form factor-bare hull, density of seawater, speed of the vessel, wetted area of bare hull and frictional resistance coefficient. The appendage resistance does not consider the resistance induced by the presence of the bow thrusters opening. It essentially depends on density of the seawater at the operating water temperature, speed of the vessel and bow thruster diameter.

The wave resistance model is based on the speed range of the vessel symbolized by the dimensionless Froude number $F_{n}$. Numerous analyses were conducted in order to produce an accurate model for the largest range of Froude numbers possible. The study utilises the prediction formula presented by Holtrop (Holtrop, J., 1984), as it indicated the best results. This term is function of volume displacement of the hull, density of the seawater, Froude number and certain numerical coefficients (such as wave resistance reduction due to bulbous bow and effects of transom stern on wave resistance).

The additional pressure resistance due to the immersed transom area and the presence of the bulbous bow depends on density of the seawater, speed of the vessel, immersed area of the transom stern, and certain numerical coefficients which take into account the effects of the Froude number based on the transom immersion.

The model ship correlation account for the effects of the hull roughness and of the still-air of the global resistance of the vessel. The study utilises an analytical method proposed by Holtrop and Mennen (Holtrop, J., and Mennen, G.G.J., 1982), based on the analysis of data resulting from speed test that have been corrected to fit with ideal trial conditions. The term is function of seawater density, speed of the vessel, wetted area of the bare hull and a correlation factor with allowance for hull roughness considerations. 
The effects of wind resistance in the model is accounted through the utilisation of the method proposed by Jensen (Schneekluth H., and Bertram, V., 1998) (Head wind) and Blendermann (Blendermann, W., 1993) (all direction of wind other then head wind).

The additional resistance that the installation of the wind turbines produces was obtained through the calculation of the total pressure loss over the row of blades, both in the upstream (first half of a revolution $\left(180^{\circ}\right)$ ) and downstream (second half of a revolution $\left(180^{\circ}\right)$ ) sections of the wind turbine.

\subsubsection{Power Plant Management routine}

The power plant management sub-module enables the matching of the calculated power requirements, provided by the marine vessel power prediction routine and the power that the engine can effectively deliver at the specific condition.

\subsubsection{Emissions model}

To predict the $\mathrm{NOx}$ and $\mathrm{CO}_{2}$ emissions from the gas turbine power plant at different operating conditions, an in-house emissions prediction model was used. The model utilises the stirred reactor method for emission predictions and produces emission indices (Celis, 2010).

\subsubsection{Trip Management routine}

This sub-module enables the detailed specifications of the mission, in terms of speeds and distances in a particular route/voyage. The voyage schedule was simulated by splitting the route into time steps that last one hour and calculating the distance of the interval through the application of equation 2.

$\Delta \mathrm{S}=\mathrm{V} * \Delta \mathrm{t}$

Where:

- $\Delta \mathrm{S}$ is the change distance

- $\quad \mathrm{V}$ is the velocity of the vessel

- $\Delta \mathrm{t}$ is the change time

The routes selection was made in order to consider the operation of the vessel in different kinds of geographical regions, thereby providing the assessment of operations in distinct weather conditions. This was done in order to assess and establish the competitiveness of the gas turbine over a diesel engine and additionally establish the suitability of the VAWTs for marine use. The routes assumed in this study therefore consider operations in the Mediterranean Sea, the North Sea, the North Atlantic Ocean and one from the North Atlantic to the South Atlantic.

The simulated voyages in this study assumed operation only in the open-sea and hence the implication/effects of Port manoeuvring and docking-undocking procedures were therefore not considered.

\subsection{Atmospheric and weather routine}

This sub-module predicts the ambient conditions and utilizes a method that exploits the utilization of three cosine functions, each one simulating a day period (Huld, A.T., et al., 2006). 
The wind speed and direction data were obtained from the Climatology of Global Ocean Winds (COGOW) and were adapted from reports of Oregon State University's Cooperative Institute for Oceanographic Satellite Studies (Risien, C.,M., and Chelton, D.B., 2006). The wind data is based on observations spread over a period of 122 months, which utilized the SeaWind scatterometer for the measurement, for a 10 year period from September 1999 to October 2009. The observations/data of wind speed and direction are collected at $10[\mathrm{~m}]$ above the sea surface. The estimated errors of the model are \pm 1.7 [m/s] for wind intensity and $\pm 14^{\circ}$ for wind direction (Risien, C.,M., and Chelton, D.B., 2006).

The wind data that was utilized for this project are from the January and July observations. This choice was made in order to analyse the different wind conditions on a winter and summer based season.

Figure 4 displays wind intensity and direction experienced by the selected ship during the trip from Southampton to New York in winter conditions. As can be noted, the wind intensity and direction change significantly during the trip, nonetheless, exploiting the VAWT main feature, which is to adapt to any wind direction, there is always a constant production of electrical power, which reduces the share from the main prime mover.

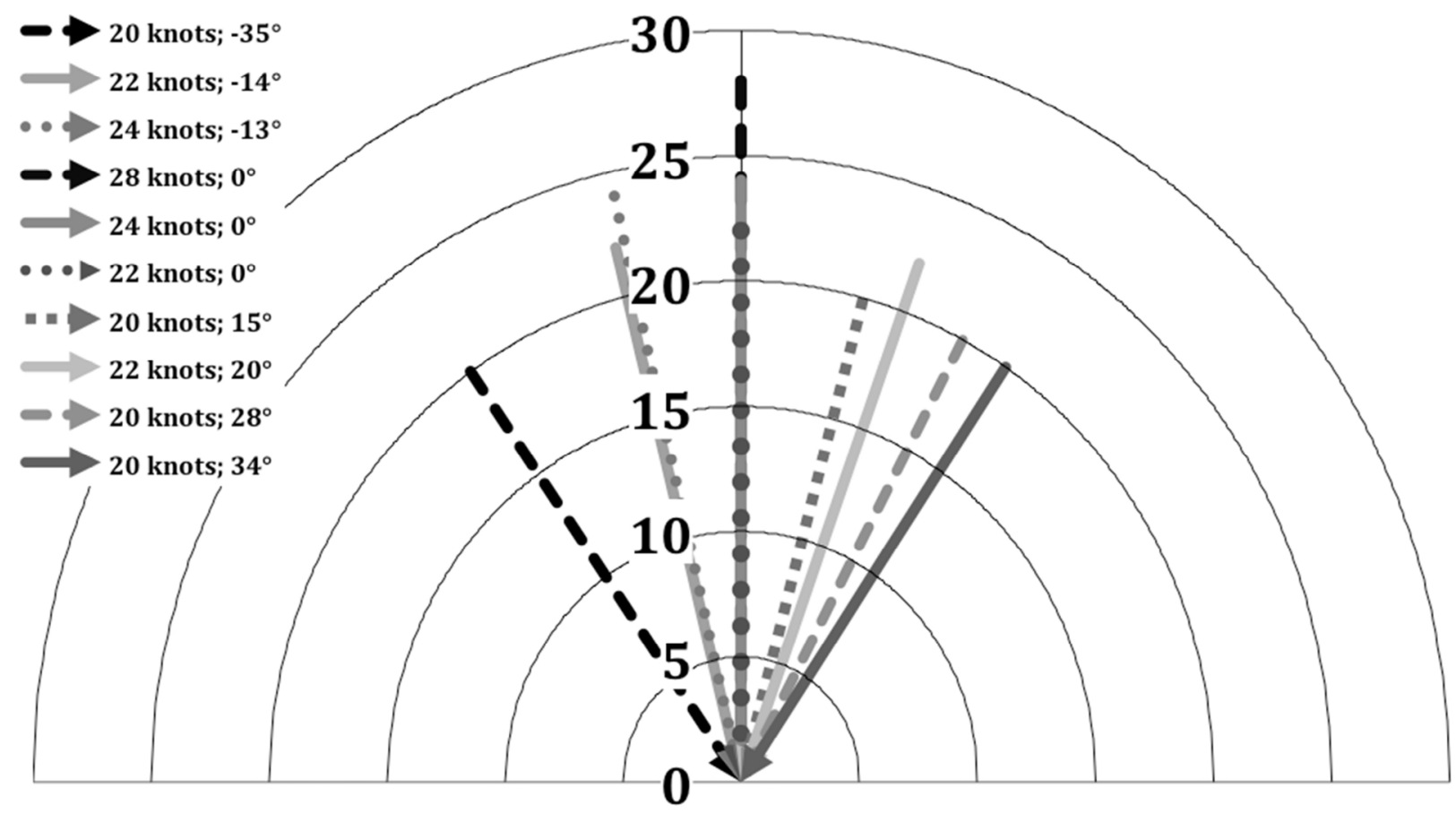

Figure 4 North Atlantic winter based wind rose Southampton-New York

\subsection{Economic Analysis}

The economic analysis was based on the savings that may be accrued by utilising a gas turbine instead of a diesel engine, derived by the lower fuel and maintenance costs and by the fuel savings that the installation of the VAWTs guarantee. 
The economic analysis was based on the costs of MDO (Marine Diesel Oil), which was taken as the average value of the real prices of the global markets. Natural gas from two different markets, one from the US (Henry Hub) and one from the UK (NBP) was also considered. The cost of both MDO and natural gas varies strongly over the years (figure 5), therefore, the perceived economic advantage of a technology over another has a certain risk.

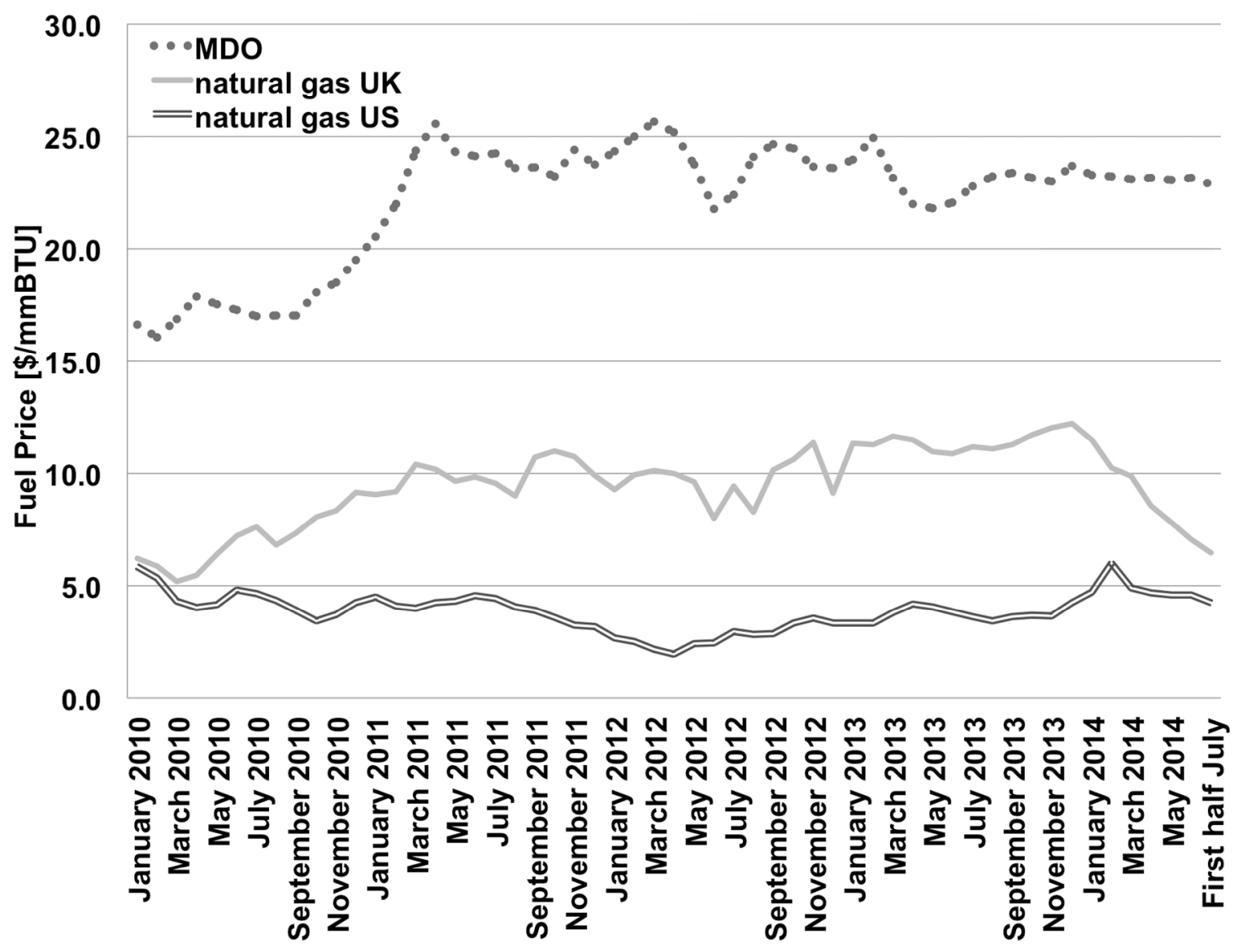

Figure 5 Monthly averaged marine fuel prices (Bunkerindex, 2014; EIA, 2014; ICE, 2014)

Another important observation that must be stated is that the economics of these systems, especially the VAWT, are directly linked to environmental taxation/rebate incentives. These economic mechanisms are often used to make environmental friendly options (such as the VAWT) more attractive. However, this study does not assume any future environmental taxation/rebate scenario. Hence, the profit generated is assumed to originate from the fuel savings that may be accrued by the installation of the VAWTs as an assisting technology and from the lower prices of natural gas over MDO, consequently producing lower annual costs.

The set of key economic parameters utilised in the analysis are presented in table 4. The reference case is assumed to be based on the latest average values of the first half of July 2014.

The economic analysis is based on the concepts of Net Present Value (NPV), discounted Payback Time (PBT), and Internal Rate of Return (IRR) (Dalton, G., et al., 2015).

The NPV is one of the key metrics utilised in industry for evaluating investments. It is calculated through equation 3. 


$$
N P V=\sum_{j=1}^{n} \frac{C F_{j}}{(1+i)^{j}}-I_{0}
$$

Where:

- $\mathrm{CF}_{\mathrm{j}}=$ fuel savings $-\mathrm{O} \& \mathrm{M}$ costs, at year $\mathrm{j}$

- $i$ is the discount rate

- $\mathrm{j}$ is the year number

- $\mathrm{I}_{0}$ is the initial investment

- $\mathrm{n}$ is the total number of years

For the reference case a discount rate of $10 \%$ was assumed (Theotokatos, G. and Livanos, G.A., 2013; Livanos, G.A., et al., 2014). A sensitivity analysis has also been carried out to investigate the influence of this parameter on the economic analysis. A lower (4\%) and higher (18\%) discount rate was considered for this study.

Gas Turbine cost

$490[\$ / k W]$

Gas Turbine installation costs

30 [\%] of the Gas Turbine cost

Gas Turbine O\&M costs

3 [\%] of the total capital cost

Diesel Engine capital cost

$349[\$ / k W]$

Diesel Engine installation costs

30 [\%] of the Diesel Engine cost

Diesel Engine O\&M costs

7 [\%] of the total capital cost

\begin{tabular}{cc}
\hline VAWT capital cost & $1500[\$ / \mathrm{kW}]$ \\
\hline VAWT installation costs & $30[\%]$ of the VAWT cost \\
\hline VAWT O\&M costs & $1.5[\%]$ of the VAWT cost
\end{tabular}

Table 4 Capital, maintenance and installation costs of the analysed technologies (Dimopoulos, G.G., et al., 2006), (Theotokatos, G. and Livanos, G.A., 2013), (Di Lorenzo, G., et al., 2012), (Al-Sulaiman, F.A., and Yilbas, B.S., 2015), (Saeidi, D., 2013).

Additionally, in order to produce a more accurate analysis, the effect of inflation was taken into account. Calculations of the NPV were executed both with a $2 \%$ inflation rate and with no inflation, through the application of equation 4

$$
N P V=\sum_{j=1}^{n} \frac{C F_{j} *(1+I R)^{j}}{(1+i)^{j}}-I_{0}
$$

Where: 
- $\quad \mathrm{IR}$ is the inflation rate

\section{RESULTS}

The simulations undertaken demonstrated a relatively small variation in the results obtained between different routes. Nevertheless, the comparison between the routes indicated that the Atlantic Ocean was a more favourable environment for the installation of the VAWTs. This is mainly attributed to the higher intensity of the wind experienced in the Atlantic Ocean when compared to the North Sea and the Mediterranean Sea. The most relevant results of the North Atlantic route (between Southampton and New York) are presented further. Additionally the study also showed that a higher gain was derived by the installation of a gas turbine burning natural gas, instead of a diesel engine burning MDO, due to the lower price of natural gas.

\section{Environmental results}

The International Maritime Organisation (IMO) currently monitors and regulates $\mathrm{NOx}, \mathrm{CO}_{2}$ and SOx emissions (Marine Environment Protection Committee, 2011). As discussed earlier and for the purposes of the study only $\mathrm{NOx}$ and $\mathrm{CO}_{2}$ were considered. It is assumed that the gas turbine is burning natural gas, consequently emitting limited quantities of SOx.

The North Atlantic route presented the highest benefit from installing of the vertical axis wind turbines voyages during January (including the corresponding return trip). Although the same trends were recognized in July trips, they were smaller. The high intensity of the January wind, as well as the suitable direction, have led to a mean reduction of NOx emissions of $14 \%$ for the gas turbine. The instantaneous NOx reduction reached peaks of $22 \%$ when experiencing wind coming from the bow with an intensity of 28 [knots], as shown in figure 6. For the diesel engine a mean reduction of $10 \%$ was observed. Moreover, it has also provided a mean reduction of $\mathrm{CO}_{2}$ emissions of $9 \%$ for the gas turbine and $8 \%$ for the diesel engine (shown in figure 7). 


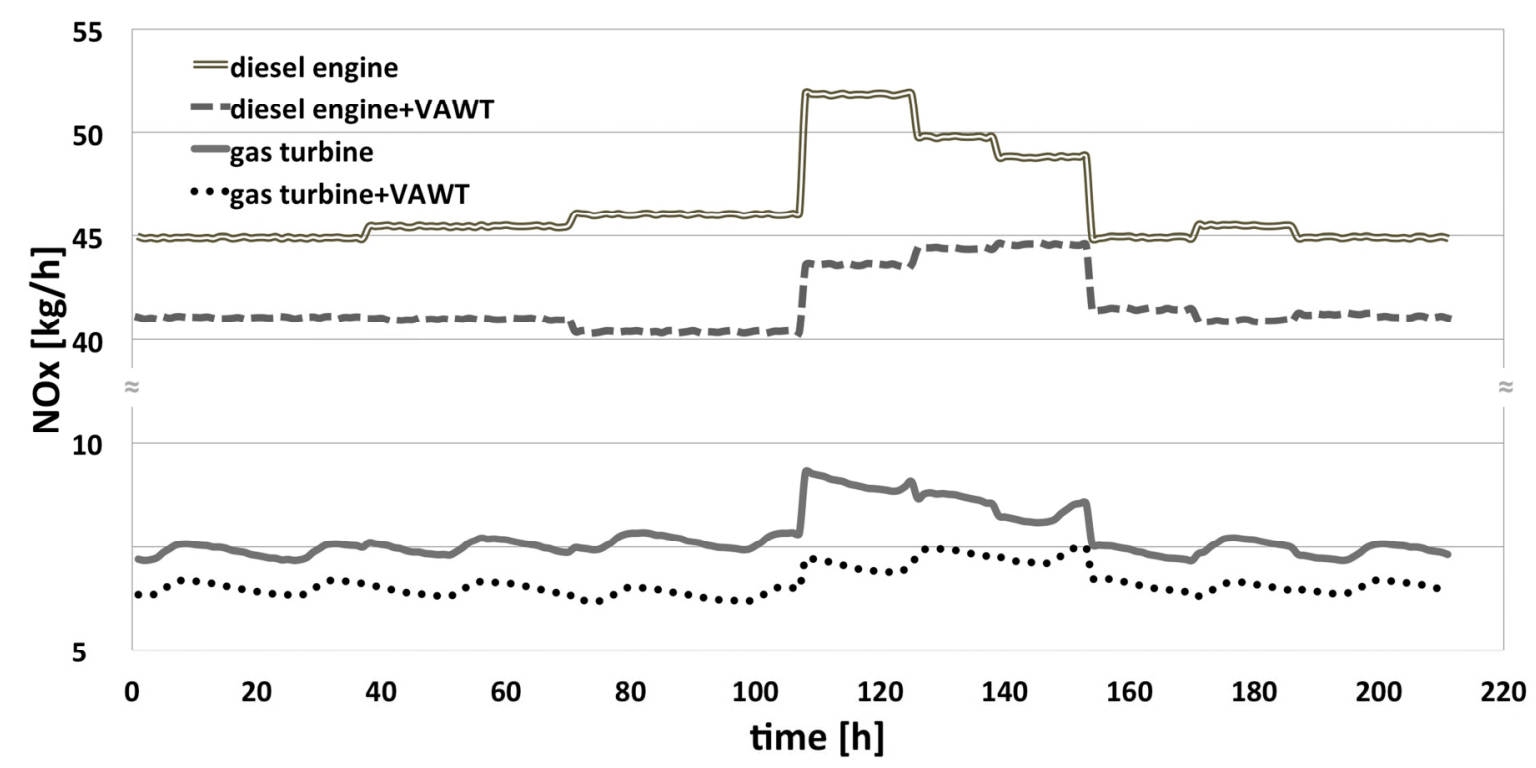

Figure $6 \mathrm{NO}_{\mathrm{x}}$ emissions $[\mathrm{kg} / \mathrm{h}]$ in the Southampton-New York route with January condition



Figure $7 \mathrm{CO}_{2}$ emissions $[\mathrm{kg} / \mathrm{h}]$ in the Southampton-New York route with January condition

Figure 8 explains the relationship between $\mathrm{CO}_{2}$ emission and fuel flow consumption. It is opined that the greatest contribution of emission reduction is due to the reduction in fuel burn. Based on the reduction in fuel burn and using scaling factors (emission indices of $2.8 \mathrm{kgCO}_{2} / \mathrm{kg}$ fuel for natural gas and $3.2 \mathrm{kgCO}_{2} / \mathrm{kg}$ fuel for the MDO (Marine Environment Protection Committee, 2009)) the results obtained for fuel flow reduction have been utilised to calculate the reduction in $\mathrm{CO}_{2}$ emissions. Therefore, as assessed for the $\mathrm{CO}_{2}$ emissions, the performance of the wind turbines in the North Atlantic Ocean route during January allows fuel savings peaks from $14 \%$ (in the gas turbine case) to $16 \%$ (in the diesel engine case). 


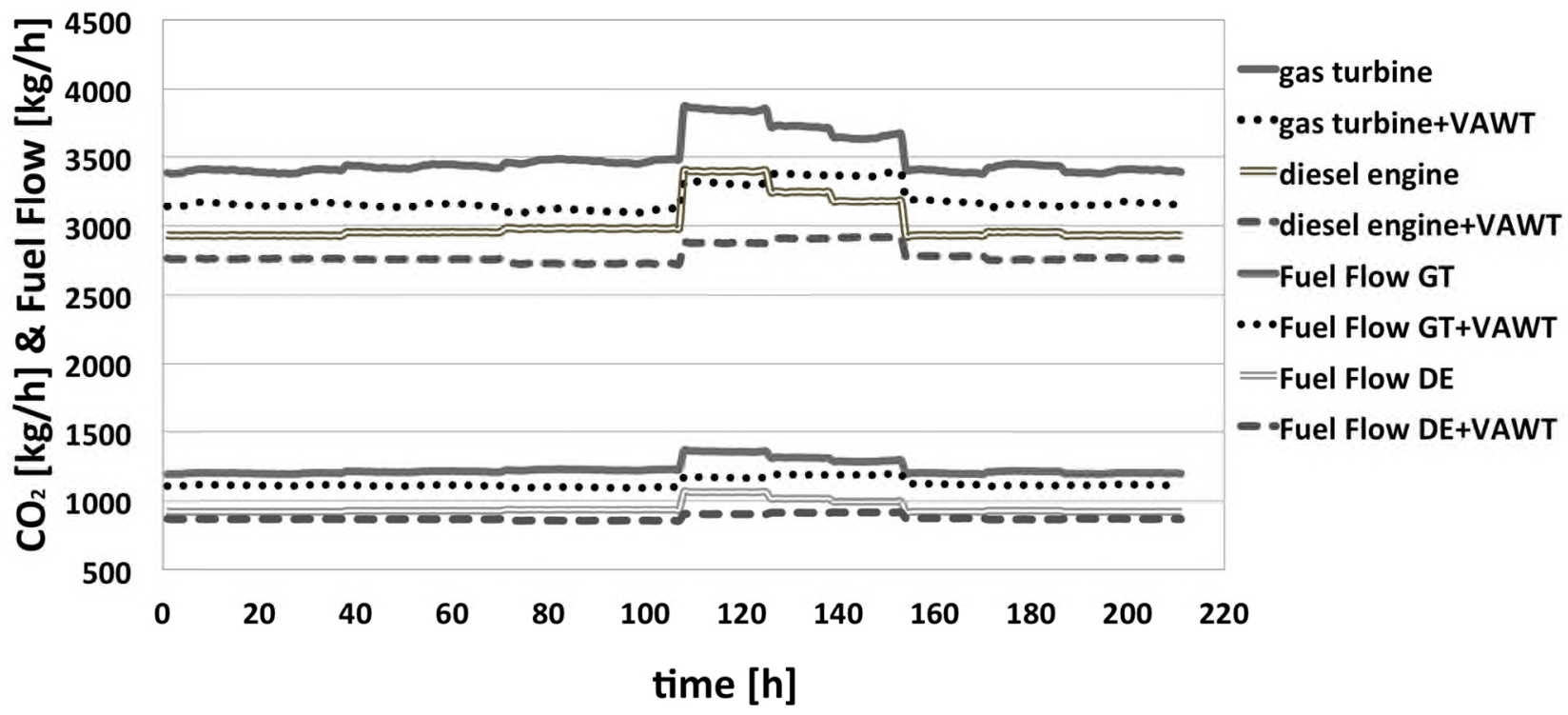

Figure $8 \mathrm{CO}_{2}$ emissions $[\mathrm{kg} / \mathrm{h}]$ and fuel flow consumption in the Southampton-New York route with weather conditions prevailing in winter (January)

The ship was assumed to be operated for an average number of 14 round trips per year. Therefore, as it can be observed in figure 9, the reduction of NOx through the installation of a gas turbine in comparison to a diesel engine was 209 [t/y], corresponding to $83 \%$ reduction of the diesel engine emissions. In contrast, the increase of $\mathrm{CO}_{2}$ emissions was calculated to be 2669 [t/y], corresponding to $16 \%$ increase for the Gas Turbine when compared to the diesel engine emissions, as shown in figure 9.

The benefits accrued through the installation of VAWTs on a gas turbine propelled ship amounts to a reduction of 2.6 [t] of NOx emissions per year, which is equivalent of a reduction of $6 \%$ of the total NOx emissions calculated for the propulsion system. Similarly the application of VAWTs on a diesel engine powered vessel indicated a reduction of 11 [t] of NOx emissions, which amounts to a reduction of $4 \%$ per year.

The implementation of VAWTs also enables the reduction of $\mathrm{CO}_{2}$ emissions. When installed in conjunction with a gas turbine propelled ship, the study indicated a reduction of 703 [t] of $\mathrm{CO}_{2}$ emissions per year (equivalent to a reduction of $4 \%$ of the total gas turbine $\mathrm{CO}_{2}$ emissions). Alternatively when installed on a diesel engine propelled ship, the utilisation of VAWTs resulted in a reduction of 555 [t] of $\mathrm{CO}_{2}$ emissions per year (amounting to $3 \%$ of the total $\mathrm{CO}_{2}$ emissions). 


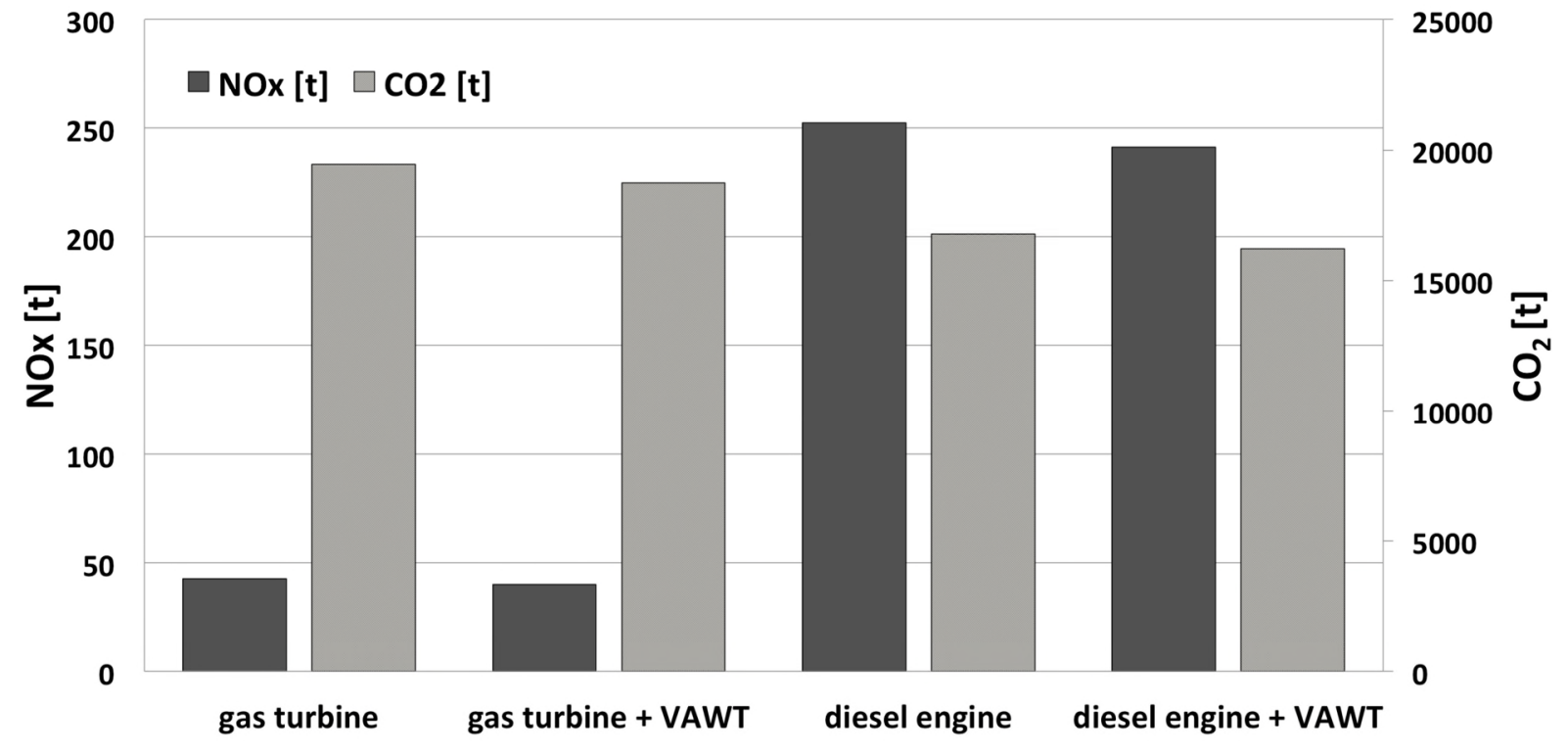

Figure 9 Total emissions per year, North Atlantic route

\subsection{Economic analysis and results}

The North Atlantic route presents the most favourable conditions to achieve the most beneficial economic advantages of installing VAWTs on a gas turbine powered vessel when compared to diesel engine solutions.

For the reference case (assuming a 10\% discount rate, no inflation and UK CNG price) when utilising a gas turbine power plant alternative instead of a diesel engine, the discounted PBT was 3 [years] and 5 [months], the IRR and the $\mathrm{NPV}_{20}$ were $34 \%$ and $5.53[\mathrm{M} \$$ ] respectively.

For the North Atlantic route (and for the North to South Atlantic one), at the current MDO price (as assumed) investment of the installation of the VAWTs is viable only when a $4 \%$ discount rate is considered, for an assumed inflation rate (0-2\%). Further when analysing the economic viability of installing VAWTs a diesel engine propelled ship, burning MDO, the annual profit, due to the fuel saving, would be $0.14[\mathrm{M} \$ / \mathrm{y}]$. This is opined to be adequate to recover the initial investment when applying discount rates that are lower than $7 \%$. These results were in contrast to those observed for the Mediterranean and North Sea routes due to non-optimal wind/weather conditions.

Figure 10 displays the required prices of MDO to have a discounted PBT of 19 years. The actual value of MDO price is very close to the values obtained through the simulations. Therefore a shorter period of time is required to return on the investment. Indeed, in order to have a discounted PBT of 10 years with a $10 \%$ discount rate and no inflation rate, the required price of MDO would need to be 1465 [\$/t], which is a value that is expected to be reached before 2035 , as assessed by McGill, R., et al. (2013). 


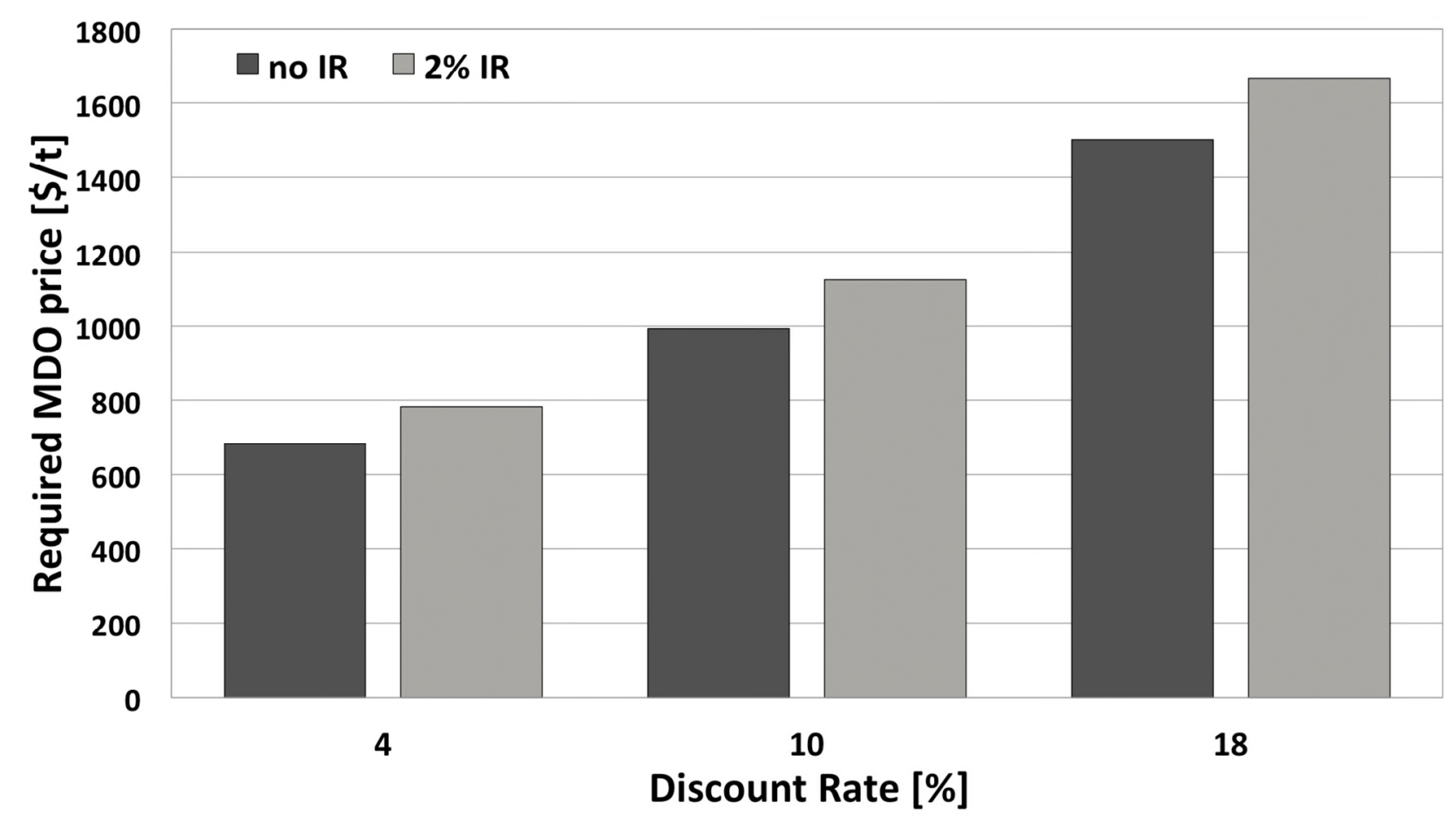

Figure 10 Required prices of MDO in order to have a discounted PBT of 19 [years]

The required prices of natural gas for a discounted PBT of 19 [years] are values that could be reached in the near future. For the $4 \%$ discount rate case, the required prices have already been observed in the last five years, when considered both for the $2 \%$ inflation rate and no inflation (11.13 $[\$ / \mathrm{mmBTU}]$ and $12.81[\$ / \mathrm{mmBTU}]$ respectively). Furthermore, required price of natural gas with a $10 \%$ discount rate and $2 \%$ inflation rate is 16.4 [\$/mmBTU], which is a high value, but still not so far from current prices.

Figure 11 displays the economic results $\left(\mathrm{NPV}_{20}\right)$ for the North Atlantic route, considering the installation of a gas turbine utilizing natural gas. The UK LNG price assumed does not guarantee a return on investment. Figure 12 shows the economic analysis results for the case study assuming the gas turbine being operated in conjunction with 2 VAWTs on board on the North Atlantic route. The required fuel price for a PBT of 19 years increases with increasing the discount rate. On the other hand, a positive inflation rate allows for a lower fuel price requirement. 


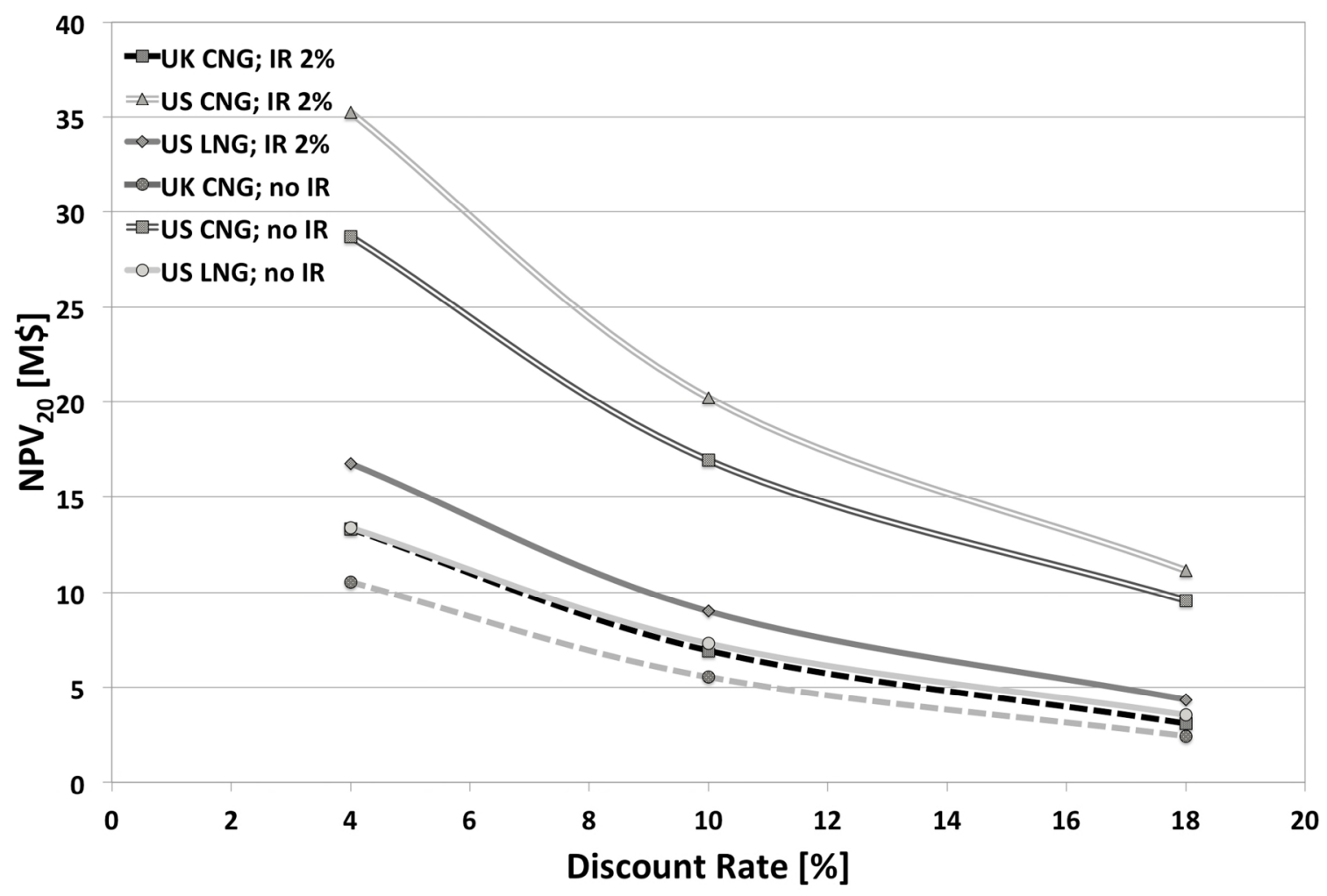

Figure 11 Installation of a gas turbine instead of a diesel engine. MDO = 925.4 [\$/t], US CNG = 4.31 [\$/mmBTU], US $\mathrm{LNG}=6.23[\$ / \mathrm{mmBTU}], \mathrm{UK} \mathrm{CNG}=6.58[\$ / \mathrm{mmBTU}]$.

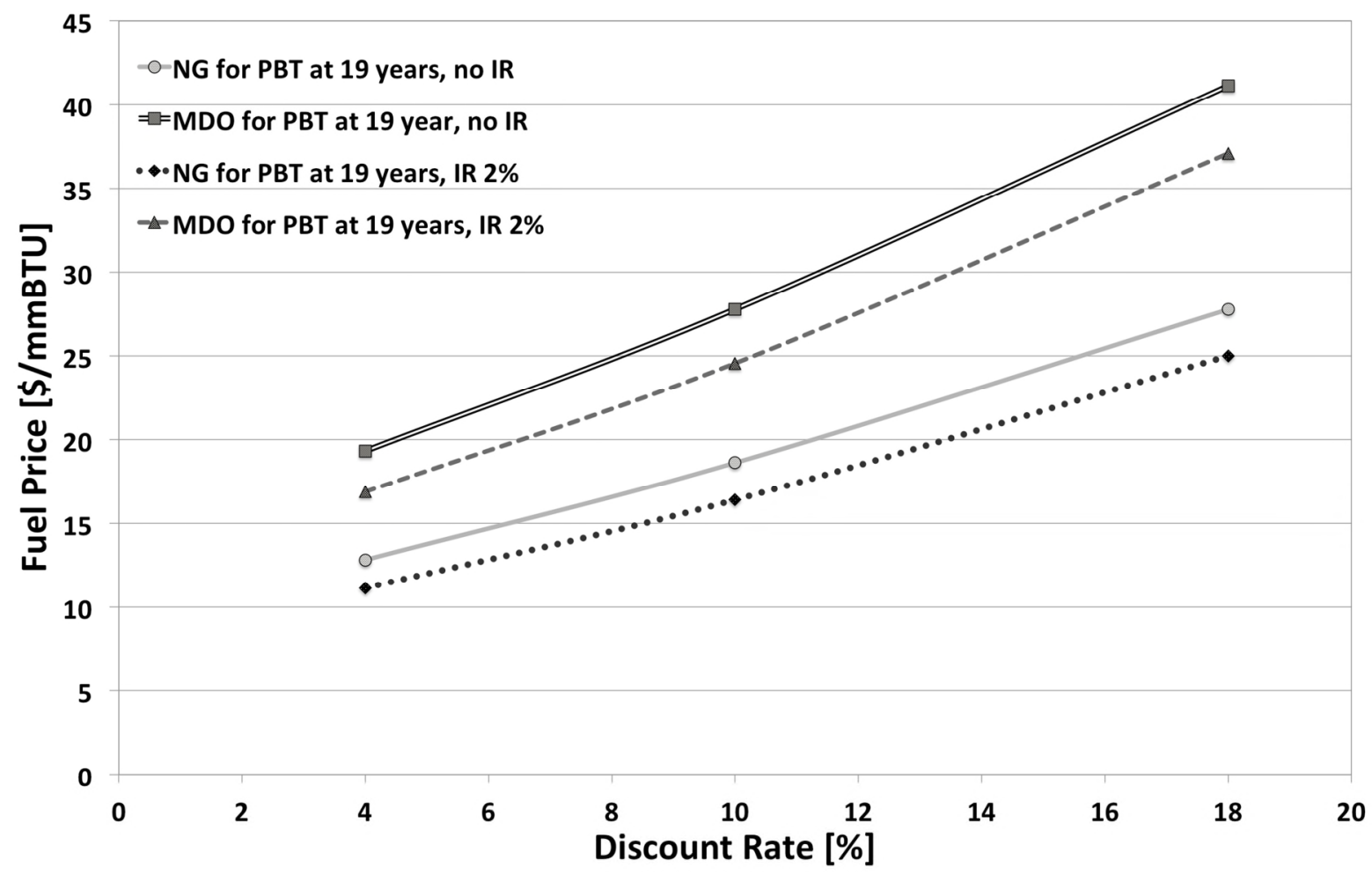

Figure 12 Required fuel price for the installation of 2 VAWTs for a PBT of 19 years. 


\section{CONCLUSIONS}

The techno economic and environmental analysis developed in this project was utilized for evaluating the efficiency of several propulsion systems under different operating conditions. Although the results obtained are very important and relevant, one pivotal point of this research is also the methodology applied and the demonstration of its importance in decision-making.

The key results from the study may be summarised as follows:

- The installation of the vertical axis wind turbines is still not very profitable for all the routes with the current policy and fuel prices. The environmental gain is surely significant, but taking into account the economic features, it is still not recommended for routes that don't experience strong wind conditions. In the actual scenario, it is found that the installation of the vertical axis wind turbines could be very advantageous when carried out on vessels that travel the Atlantic Ocean. In fact, the routes assessed in the Atlantic Ocean were characterized by high fuel consumption and especially by strong wind conditions, which favour power production by the vertical axis wind turbines.

- Another relevant result that was obtained was the higher advantage that the vertical axis wind turbines produce when installed on a diesel engine propelled ship, instead on a gas turbine propelled ship. This was due to two main reasons. Firstly the simulated gas turbine was a simple cycle gas turbine which presents a higher fuel consumption compared to the diesel engine when operating in off-design conditions. The second reason is that the price of the MDO is far higher than the price of natural gas, therefore, the savings derived by the installation of the vertical axis wind turbines produce a greater effect in the diesel engine case. Indeed, with the current market prices, if taking into account a discount rate lower than $7 \%$, the installation of the vertical axis wind turbines over a ship propelled by a diesel engine travelling in the Atlantic Ocean is already lucrative.

- The choice of a powerplant is strongly affected by the market price of marine fuels. The price gap between Marine Diesel Oil and natural gas is forecast to increase, favouring the gas turbine scenario solution.

- A result that was extremely significant, that was verified for all the voyages, was the higher fuel consumption, and therefore the higher $\mathrm{CO}_{2}$ emissions, of the gas turbine due to the lower efficiency, in comparison to the diesel engine.

- Concerning the environmental features, except for the $\mathrm{CO}_{2}$ emissions, which were higher due to the higher fuel consumption, due to the lower efficiency, which anyhow are not regulated for a ship propelled by a gas turbine burning natural gas, all the other pollutant emissions had a lower result when the gas turbine was employed.

To conclude, the analysis developed showed how the techno economic and environmental analysis applied in the marine sector is a very valuable tool to estimate several engine configurations and to assess the best solution established on an accurate and rigorous basis. 


\section{ACKNOWLEDGEMENTS}

The authors acknowledge the kind support and guidance of Professor Giampaolo Manfrida and Professor Daniele Fiaschi of Florence University throughout the project, especially regarding the modelling of the vertical axis wind turbine.

\section{REFERENCE}

Al-Sulaiman, F.A., and Yilbas, B.S., (2015), "Thermoeconomic analysis of shrouded wind turbines", in: Energy Conversion and Management, Vol. 96, pp. 599-604.

Alexiou, A., Roumeliotis, I., Aretakis, N., Tsalavoutas, A., and Mathioudakis, K. (2012) Modeling Contra-Rotating Turbomachinery Components for Engine Performance Simulations: The Geared Turbofan With Contra-Rotating Core Case. ASME J Gas Turb Pwr, 134(11), November. DOI: 10.1115/1.4007197.

Alfonsín, V., Suarez, A., Cancela A., Sanchez A., Maceiras, R., (2014), “Modelization of hybrid systems with hydrogen and renewable energy oriented to electric propulsion in sailboats”, in: International Journal of Hydrogen Energy, Vol., 39, pp. 11763-11773.

Andrews, J., and Shabani, B., (2012), "Re-envisioning the role of hydrogen in a sustainable energy economy", in: International Journal of Hydrogen Energy, Vol., 37, pp. 1184-1203.

Bergeson, L., Greenwald, C., K., (1985), “Sail Assist Developments 1979-1985”, in: Journal of Wind Engineering and Industrial Aerodynamics, Elsevier Science Publisher, Vol. 19, Amsterdam, Netherlands, p. 45-114.

Blendermann, W., (1993), "Parameter identification of wind loads on ships", in: Journal of Wind Engineering and Industrial Aerodynamics, Vol. 51, pp. 339-351.?

Bockmann, E., Steen, S., (2011), "Wind Turbine Propulsion of Ships", in: Second International Symposium on Marine Propulsors, Hamburg, Germany.

Bonet, M.U., Doulgeris, G., Pilidis P., (2010), “Assessment of a Marine Gas Turbine Installation on a Liquefied Natural Gas Carrier", in: Nausivios Chora 2010, Hellenic Naval Academy.

Brynolf , S., Fridell, E., Andersson, K., (2014), “Environmental assessment of marine fuels: liquefied natural gas, liquefied biogas, methanol and bio-methanol", in: Journal of Cleaner Production, Vol. 74, pp. 86-95.

Bunkerindex, (2014), Bunker Index available at: http://www.bunkerindex.com/prices/bixfree.php?priceindex id=4 (accessed $23^{\text {rd }}$ July 2014).

Burel, F., Taccani R., Zuliani, N., (2013), “Improving sustainability of maritime transport through utilization of Liquefied Natural Gas (LNG) for propulsion”, in: Energy, Vol. 57, pp. 412-420. 
Camilleri, W., Anselmi, E., Sethi, V., Laskaridis, P., Rolt, A., Cobas, P. (2014) Performance characteristics and optimisation of a geared intercooled reversed flow core engine, in: Proceedings of the Institution of Mechanical Engineers, Part G: Journal of Aerospace Engineering 0954410014530679, doi: 10.1177/0954410014530679.

Celis, C. (2010) Evaluation and Optimisation of Environmentally Friendly Aircraft Propulsion Systems. PhD thesis, Cranfield University, UK

Dalton, G., Allan, G., Beaumont, N., Georgakaki, A., Hacking, N., Hooper, T., Kerr, S., O’Hagan, A.M., Reilly, K., Ricci, P., Sheng, W., Stallard, T., (2015), "Economic and socio-economic assessment methods for ocean renewable energy: Public and private perspectives", in: Renewable and Sustainable Energy Reviews, Vol. 45, pp. 850-878.

Di Lorenzo, G., Pilidis, P., Witton, J., Probert, D., (2012), “Monte-Carlo simulation of investment integrity and value for power-plants with carbon-capture", in: Applied Energy, Vol. 98, pp. 467-478.

Dimopoulos, G.G., Kougioufas, A.V., Frangopoulos, C.A., (2006) "Synthesis, design and operation optimization of a marine energy system", in: Energy, Vol. 33, Issue 2, pp. 180-188.

Doulgeris, G., Korakianitis, T., Pilidis P., Tsoudis, E., (2012), “Techno-economic and environmental risk analysis for advanced marine propulsion systems", in: Applied Energy, Vol. 99, pp. 1-12.

EIA, (2014), Henry Hub Natural Gas Spot Price, available at: http://www.eia.gov/dnav/ng/hist/rngwhhdm.htm (accessed $23^{\text {rd }}$ July 2014).

El-Gohary. M.M., (2013), "Overview of Past, Present and Future Marine Power Plants", in: Journal of Marine Science and Application, Vol. 12, pp. 219-227.

García-Martos, C., Rodríguez, J., Sánchez, M.J., (2013), “Modelling and forecasting fossil fuels, $\mathrm{CO}_{2}$ and electricity prices and their volatilities", in: Applied Energy, Vol. 101, pp. 363-375.

Goulos, I., Pachidis, V., Celis, C, D’Ippolito, R., Stevens, J., (2010), Simulation Framework Development for Aircraft Mission Analysis, GT2010-23379, Proceedings of GT2010, ASME Turbo Expo 2010, Power for Land, Sea and Air, Glasgow, UK, 2010.

Hirdaris, S.E., Cheng Y.F., Shallcross P., Bonafoux J., Carlson D., Prince B., Sarris G.A., (2014), "Considerations on the potential use of Nuclear Small Modular Reactor (SMR) technology for merchant marine propulsion", in: Ocean Engineering, Vol. 79, pp. 101-130.

Hirsch, H., Mandal, A.C., (1987), “A Cascade Theory for the Performance of Darrieus Wind Turbines", in: Wind Engineering, Vol. 11, No. 3, pp. 164-175.

Holtrop, J., Mennen, G.G.J., (1982) “An approximate power prediction method", in: International Shipbuilding Progress, Vol. 29. 
Huaa, J., Wub, Y.H., Jina, P.F., (2008), “Prospects for renewable energy for seaborne transportation-Taiwan example", in: Renewable Energy, Vol. 33, pp. 1056-1063.

Huld, A.T., Šúri, M., Dunlop, D.E., Micale, F., (2006), “Estimating Average Daytime and Daily Temperature profiles within Europe", in: Environmental Modelling and Software, Vol. 21, pp. 1650-1661

ICE, (2014), Indices-UK and European natural gas, available at: https://www.theice.com/marketdata/reports/80 (accessed $23^{\text {rd }}$ July 2014).

Kyprianidis K.G., Grönstedt T., Ogaji, S.O.T., Pilidis, P., Singh, R., (2011), “Assessment of Future Aero Engine Designs with Intercooled and Intercooled Recuperated Cores", in: Journal of Engineering for Gas Turbines and Power, Vol. 133.

Kyprianidis K.G., Quintero, R.F.C., Pascovici, D.S., Ogaji, S.O.T., Pilidis, P., Kalfas, A.I., (2008), “EVA - A Tool for EnVironmental Assessment of Novel Propulsion Cycles", ASME Turbo Expo 2008 Proceedings, GT2008-50602.

Kyprianidis, K.G., Rolt, A., and Grönstedt, T. (2014) Multidisciplinary Analysis of a Geared Fan Intercooled Core AeroEngine, ASME Journal of Gas Turbine and Power, 136(1), January. DOI: 10.1115/1.4025244.

Lambrecht, M., K., Klintworth, J., W., Jordaan, M., G., Bunt, E., A., (1994), "Model investigation of aerofoil sails as auxiliary ship propulsion devices", in: R\&D Journal, Vol. 10, No 3.

Leloup, R., Roncin, K., Bles, G., J.-B. Leroux, J.B., Jochum, C., Parlier, Y., (2014), “Kite and classical rig sailing performance comparison on a one design keel boat", in: Ocean Engineering, Vol. 90, pp. 39-48.

Lingwood, J., (1999), Significant Ships of 1998, The Royal Institution of Naval Architects, London, UK.

Livanos, G.A., Theotokatos, G., Pagonis, D.N., (2014), “Techno-economic investigation of alternative propulsion plants for Ferries and RoRo ships", in Energy Conversion and Management, Vol. 79, pp. 640-651.

MacMillan, W. L. (1974) Development of a modular-type computer program for the calculation of gas turbine offdesign performance (PhD Thesis) Cranfield University, Cranfield.

MAN B\&W, (2013), L32/40 Project Guide-Marine, Four-stroke GenSet compliant with IMO Tier II, available at: http://www.mandieselturbo.com/download/documents/ProjectGuides4Stroke/L32-40 GenSet Tierll.pdf (accessed $5^{\text {th }}$ July 2014).

Marinai, L., Probert, D., and Singh, R.(2004) Prospects for aero gas-turbine diagnostics: a review, Applied Energy, Elsevier, vol. 79, issue 1, pages 109-126.

Marine Environment Protection Committee, (2009), Guidelines for voluntary use od the ship energy efficiency operational indicator (EEOI), report number Ref. T5/1.01 MEPC.1/Circ.684, available at: http://www.imo.org/blast/blastDataHelper.asp?data id=26531\&filename=684.pdf (accessed 28 ${ }^{\text {th }}$ June 2014). 
Marine Environment Protection Committee, (2011), Amendments to the Annex of protocol of 1997 to amend the international convention for the prevention of pollution from ships, 1973, as modified by protocol of 1978 relating thereto, report number RESOLUTION available http://www.imo.org/MediaCentre/HotTopics/GHG/Documents/eedi\%20amendments\%20RESOLUTION\%20MEPC203 \%2062.pdf (accessed $28^{\text {th }}$ June 2014).

McGill, R., Remley, W., B., Winther, K., (2013), Alternative Fuels for Marine Applications, A report from IEA Advanced Motor Fuels Implementing Agreement, May 2013.

Najafi Saatlou, E., Kyprianidis K.G., Sethi, V., Abu, A.O., Pilidis, P. (2014) On the trade-off between minimum fuel burn and maximum time between overhaul for an intercooled aeroengine, in: Proceedings of the Institution of Mechanical Engineers, Part G: Journal of Aerospace Engineering 0954410013518509, doi: 10.1177/0954410013518509.

NASA (2014) Technology Readiness Level, available at: http://www.nasa.gov/content/technology-readinesslevel/\#.U5Vnl IdVKY (accessed $1^{\text {st }}$ June 2014).

Notteboom, T.E., Vernimmen, B., (2009), "The effect of high fuel costs on liner service configuration in container shipping”, in: Journal of Transport Geography, Vol. 17, pp. 325-337.

Ogaji, S.O.T., Pilidis, P. and Sethi, V., (2009), “Advanced Power Plant Selection: The TERA (Techno-economic Environmental Risk Analysis) Framework”, ISABE 2009 Proceedings, ISABE-2009-1115.

Parker, J., (2013), Future Ship Powering Options: Exploring alternative methods of ship propulsion, report number 9781-909327-01-6, Royal Academy of Engineering, London, UK.

Pope, K., Dincer, I., Naterer, G.F., (2010), “Energy and exergy efficiency comparison of horizontal and vertical axis wind turbines", in: Renewable Energy, Vol. 35, pp. 2102-2113

Risien, C.M., Chelton, D.B., (2006) “A satellite-derived climatology of global ocean winds", in: Remote Sensing of Environment, Vol. 105, Issue 3, pp. 221-236.

Rojon, I., Dieperink, C., (2014), “Blowin' in the wind? Drivers and barriers for the uptake of wind propulsion in international shipping", in: Energy Policy, Vol. 67, pp. 394-402.

Saeidi, D., Sedaghat, A., Alamdari, P., Alemrajabi, A.A., (2013), “Aerodynamic design and economical evaluation of site specific small vertical axis wind turbines", in: Applied Energy, Vol. 101, pp. 765-775.

Schneekluth H., Bertram, V., (1998) Ship Design for Efficiency and Economy (2 ${ }^{\text {nd }}$ edition), Butterworth-Heinemann, Oxford, UK.

Shukla, P., C., Kunal, G., (2009), "Revival of Modern Wing Sails for the propulsion of Commercial Ships", in: World Academy of Science, Engineering and Technology International Journal of Physical, Nuclear Science and Engineering, Vol. 3, No. 3. 
Theotokatos, G., Livanos, G.A., (2013), "Techno-economical analysis of single pressure exhaust gas waste heat recovery systems in marine propulsion plants", in: Journal of Engineering for the Maritime Environment, Vol. 227, Issue 2, pp. 83-97.

Traut, M., Gilbert, P., Walsh, C., Bows, A., Filippone, A., Stansby, P., Wood, R., (2014), "Propulsive power contribution of a kite and a Flettner rotor on selected shipping routes", in: Applied Energy, Vol. 113, pp. 362-372.

Vergara, J., McKesson, C., Walczak, M., (2012), "Sustainable energy for the marine sector", in: Energy Policy, Vol. 49, pp. 333-345.

Woodyard, D., (2004), Pounder's Marine Diesel Engines and Gas Turbines (8th ed), Elsevier, Oxford, United Kingdom.

Xu, L., Kyprianidis, K.G., and Grönstedt, T. (2013) Optimization Study of an Intercooled Recuperated Aero-Engine, AIAA Journal of Propulsion and Power, 29(2), March-April. DOI: 10.2514/1.B34594. 


\section{Techno economic and environmental assessment of wind assisted marine propulsion systems}

Talluri, L.

Elsevier

L. Talluri, D.K. Nalianda, K.G. Kyprianidis, T. Nikolaidis, P. Pilidis, Techno economic and environmental assessment of wind assisted marine propulsion systems, Ocean Engineering, Volume 121, 15 July 2016, pp301-311

http://dx.doi.org/10.1016/j.oceaneng.2016.05.047

Downloaded from Cranfield Library Services E-Repository 